\title{
CDISC SEND Tumor Findings Test Code Terminology
}

National Cancer Institute

\section{Source}

National Cancer Institute. CDISC SEND Tumor Findings Test Code Terminology. NCI

Thesaurus. Code C90006.

The terminology that includes concepts relevant to the Clinical Data Interchange Standards Consortium (CDISC) Standard for the Exchange of Non-clinical Data (SEND) tumor findings test short names. 